\title{
Primary Exploration on Tribological Behavior of Perrhenates as Lubricating Oil Additive in a Wide Temperature Range
}

\author{
Wang Junhai* Zhang Lixiu Zhang Ke
}

(School of Mechanical Engineering, Shenyang Jianzhu University, Shenyang 110168, China)

Keywords: Perrhenates; Oil additive; Wide temperature range; High temperature; Antifriction

\begin{abstract}
The perrhenates of Calcium, Copper and Lead used as oil additive were synthesized via aqua-solution method in this study, and their tribological properties were examined by UMT-2M testing machine. In addition, investigations were performed using XRD, SEM-EDS, DTA/TG to explain the possible mechanism of antifriction behaviors. The experimental results suggested that all of synthesized perrhenates were crystal powder, and contents were close to the stoichiometic values. It was found that perrhenates additive significantly decreased the friction and wear compared to the base oil lubricant under high temperatures. Several lubricating properties and effects due to the perrhenates were presented. It was established that a antifriction and low-shear layer was forming on the disc surfaces. These prevented the direct contact of sliding surfaces effectively, thus decreased the friction. The antifriction behaviors of perrhenates in wide temperature range implied that some of them could be developed as the candidate of additives for a hybrid lubricating mode.
\end{abstract}

\section{Introduction}

Most of solid lubricant are ineffective in the high temperature conditions because of oxidation such as $\mathrm{MoS}_{2}$ [1-3]. The equipments which task in the air environment must generate oxide film on the surface of the moving parts, no matter with or without lubricating. Therefore, if a kind of solid lubricant which could not only work in the room temperature combined with oil, but they have also the lubricating ability after oxidative decomposition of oil can be designed, the continuous lubrication on the surface of moving parts in wide temperature range will be achieved.

Besides these solid lubricants have lubricating ability themselves, their corresponding decompositions exhibit antifriction characteristic at high temperature. The sulfur, phosphor and fluorine element should not be contained in order to environmental friendly. The oxides as solid lubricant at high temperature had been studied systematically by some reserachers, and their reports showed that soft oxides with low shear strength were potential high temperature solid lubricants [4,5]. For instance, the rare metal Rhenium was easily to be oxidized in air condition and its corresponding product $\mathrm{Re}_{2} \mathrm{O}_{7}$ was subliming at about $300^{\circ} \mathrm{C}$.

The perrhenates had been synthesized at the beginning of last century, and recently some their properties such as crystal structure had been searched for by many investigators [6-7]. However, little research has been done on the antifriction behaviors of perrhenates. This paper aims to utilize the perrhenates as oil additive to achieve a wide temperature range lubricating.

\section{Experimental}

The synthesizing of perrhenates method is as follows: Dissolving 0.003 mol high-purity rhenium powder in $20-\mathrm{mL} 30 \%$ aqueous hydrogen peroxide yields a colorless solution of perrhenic acid, $\mathrm{HReO}_{4}$. Then according to stoichiometric amount, and 30\% excess of metal compose of $\mathrm{Ca}, \mathrm{Cu}, \mathrm{Pb}$ are added into $\mathrm{HReO}_{4}$ respectively. The reaction starts at a temperature between $50^{\circ} \mathrm{C}$ and $60^{\circ} \mathrm{C}$ under release of gas bubbles. At the end of the reaction, the excess debris is filtered off, and the solution is kept on a water bath $\left(80^{\circ} \mathrm{C}\right)$ until a thin crystalline surface layer formed. The solution is then removed from the water bath and kept at room temperature.

The crystal structure of products will be analyzed by D/max-2500PC X-ray diffractometer(Cu K 
radiation source); the morphology and composition of products are obtained by FEI INSPECT F50 scanning electron microscope.

Table.1 Properties of the base oil

\begin{tabular}{ccccc}
\hline Properties & $\begin{array}{c}\text { Kinematic viscosity, } \\
\mathrm{cSt} @ 40^{\circ} \mathrm{C}\end{array}$ & $\begin{array}{c}\text { Kinematic viscosity, } \\
\mathrm{CSt} @ 100^{\circ} \mathrm{C}\end{array}$ & $\begin{array}{c}\text { Flash } \\
\text { temperature } /{ }^{\circ} \mathrm{C}\end{array}$ & $\begin{array}{c}\text { Heat decomposition } \\
\text { temperature } /{ }^{\circ} \mathrm{C}\end{array}$ \\
\hline PETE & 65 & 13 & 300 & 316 \\
\hline
\end{tabular}

The pentaerythritol ester (PETE) is chosen as the base oil because of its excellent comprehensive performance, and its properties were shown in the table 1. Then the perrhenates and a dose of surfactant ( Polyoxyethylene octyphenyl ether, Sodium dodecyl sulfate ) are added into the base oil. The tribological properties are investigated with ball-on-disk cycle sliding mode in UMT-2M testing machine. The frictional experimental conditions are as follows: nominal contact unit load is $200 \mathrm{~g}$, and sliding speed is $37.70 \mathrm{~mm} / \mathrm{s}$. The rubbing pairs are $\mathrm{Si}_{3} \mathrm{~N}_{4}$ ceramic ball with the diameter of $4 \mathrm{~mm}$, the surface roughness of $0.02 \mu \mathrm{m}$; and the GH4169 superalloy disc with the diameter of 50 $\mathrm{mm}$, the surface roughness of $0.2 \mu \mathrm{m}$.Before the test, certain load imposes on the surface of disc for 10 minutes to make a groove in the disc and eliminate the surface roughness impact. The oil with or without the perehenates is added in the wear scar groove. 8 minutes frictional testing proceeds at $22^{\circ} \mathrm{C}, 200^{\circ} \mathrm{C}, 350^{\circ} \mathrm{C}, 450^{\circ} \mathrm{C}$ and $600^{\circ} \mathrm{C}$ respectively at ambient conditions.

\section{Results and Discussions.}
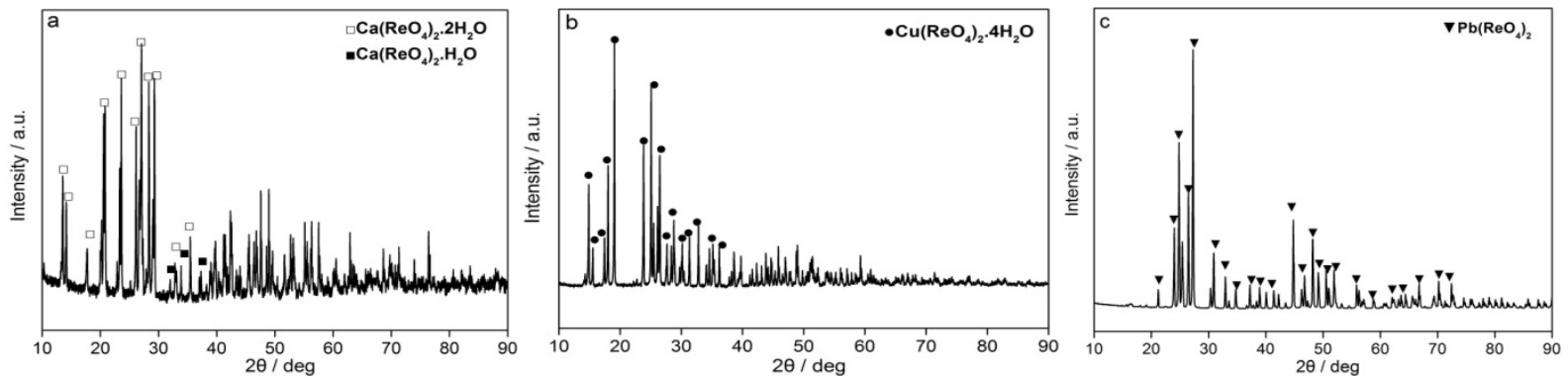

Fig.1 XRD Patterns of the different synthesized perrrhenates

(a) $\mathrm{Ca}\left(\mathrm{ReO}_{4}\right)_{2}$ (b) $\mathrm{Cu}\left(\mathrm{ReO}_{4}\right)_{2}$ (c) $\mathrm{Pb}\left(\mathrm{ReO}_{4}\right)_{2}$

Fig 1 shows the XRD of all products. Measured interplanar spacing values were close to standard values. Certain measured peak value of relative intensity was inconsistent with standard value, because the synthesized method in this paper was inconsistent with synthesized method of standard PDF, and it was difficult to control the content of crystal water. The above two points resulted in the different contents of crystal water of products. Moreover, it related to the preferred orientation of the crystal, and it did not influent identification of the synthesized products in this paper.

The synthesized method in this study was difficult to control the grain size of products. Further, most of products include crystal water, which caused the grain size increased. Among the synthesized products in the Fig 2, the grain size of perrhenates were between $100 \mu \mathrm{m}$ and $200 \mu \mathrm{m}$. Most of perrhenates exhibited scaly or loose layered crystallization. Perhaps this special scaly crystallization was benefit to antifriction.

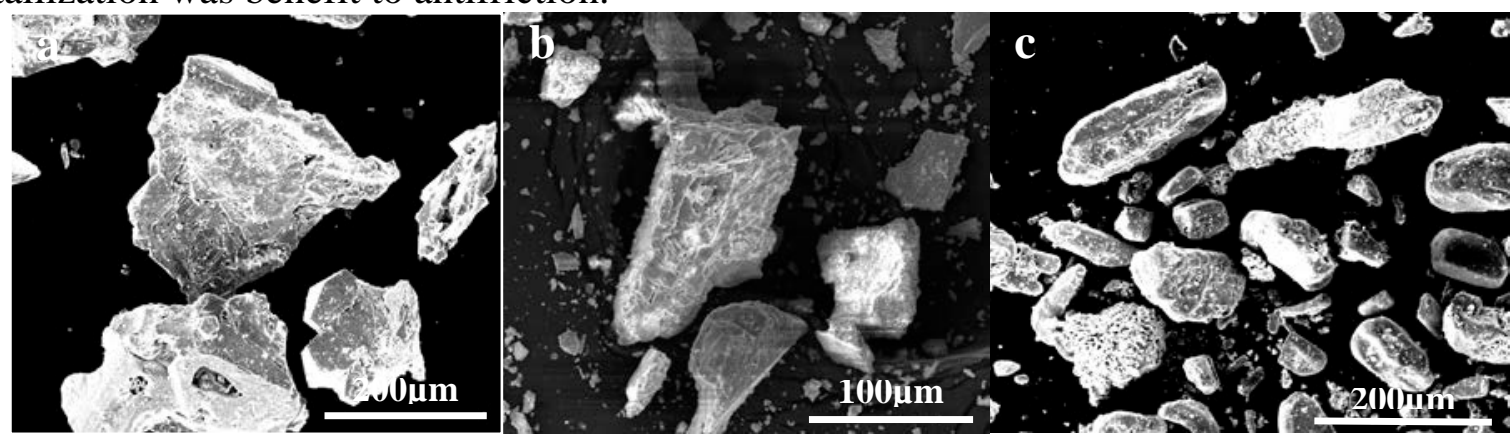

Fig.2 SEM images of different synthesized perrhenates

(a) $\mathrm{Ca}\left(\mathrm{ReO}_{4}\right)_{2}$ (b) $\mathrm{Cu}\left(\mathrm{ReO}_{4}\right)_{2}$ (c) $\mathrm{Pb}\left(\mathrm{ReO}_{4}\right)_{2}$ 
To compare the results under different lubricating oil additive, each group experiment was carried out under the same conditions. The results of the friction coefficient of perrhenates as oil additive from room temperature to $600^{\circ} \mathrm{C}$ were shown in Fig 3. The friction coefficients of oil with perrhenates were coincidence with that of oil without perrhenaes below $200^{\circ} \mathrm{C}$. It was suggested that the fluid lubrication played the major role in this condition. Under that temperature, the base oil provided a excellent lubricating behavior itself, while the perrhenates as additive did not increase the friction coefficient obviously. At $350^{\circ} \mathrm{C}$ the oil begin to volatile or decompose, and the perrhenates played their role in the transition from fluid lubrication to boundary lubrication. Therefore, the friction coefficients with perrhenates additive were lower than the corresponding oil without additive. Although the friction coefficients under high temperatures with different additives shared the same final tendency, the friction coefficients varied. Throughout the experimental stage the friction coefficient with the $\mathrm{Pb}\left(\mathrm{ReO}_{4}\right)_{2}$ additive had no obvious change and remain below 0.2, which was lower than that with other powder additives.

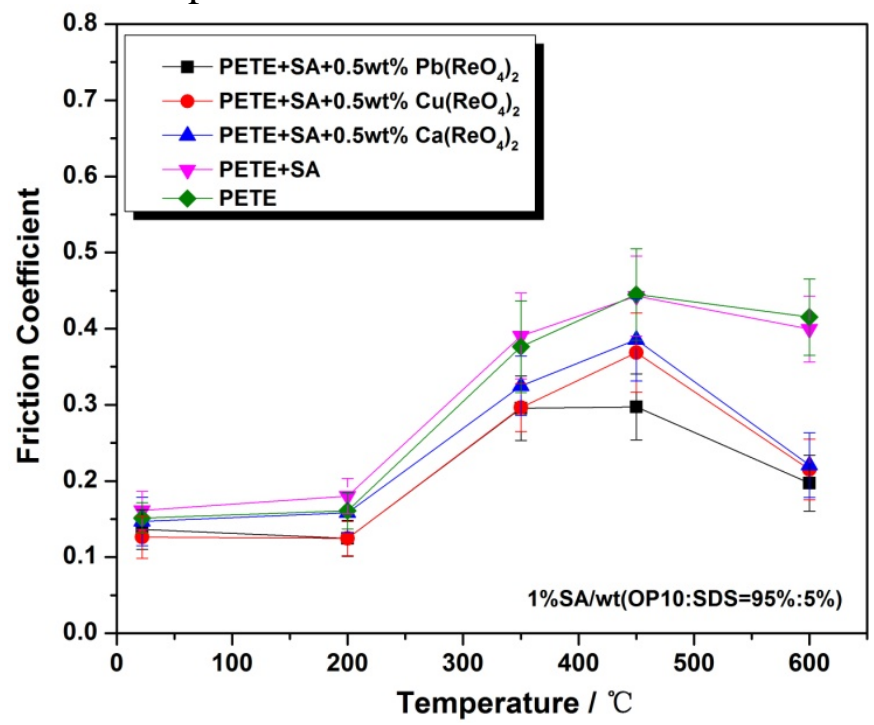

Fig.3 The friction coefficient values of different lubricants at different temperatures

The Fig 4 was the SEM images of worn tracks on the disc lubricated by PETE with and without synthesized perrhenate. The friction coefficients are different, because the different perrhenates additive have different abilities of film formation at the same experimental condition. The SEM analysis of the worn track lubricated with pure PETE confirmed that obvious plastic deformation occurred on the disc surface with large pieces of wear debris on the worn track. The wear mechanism was abrasive wear(Fig 4(a)). As fig 4(b) showed, the worn track with $\mathrm{Ca}\left(\mathrm{ReO}_{4}\right)_{2}$ as lubricating additive appears a compact film. Moreover, the film formed by perrhenates in the worn track spreads easily due to pressure and high temperature melting with temperature increased, and even the film formed clean enamel layer.

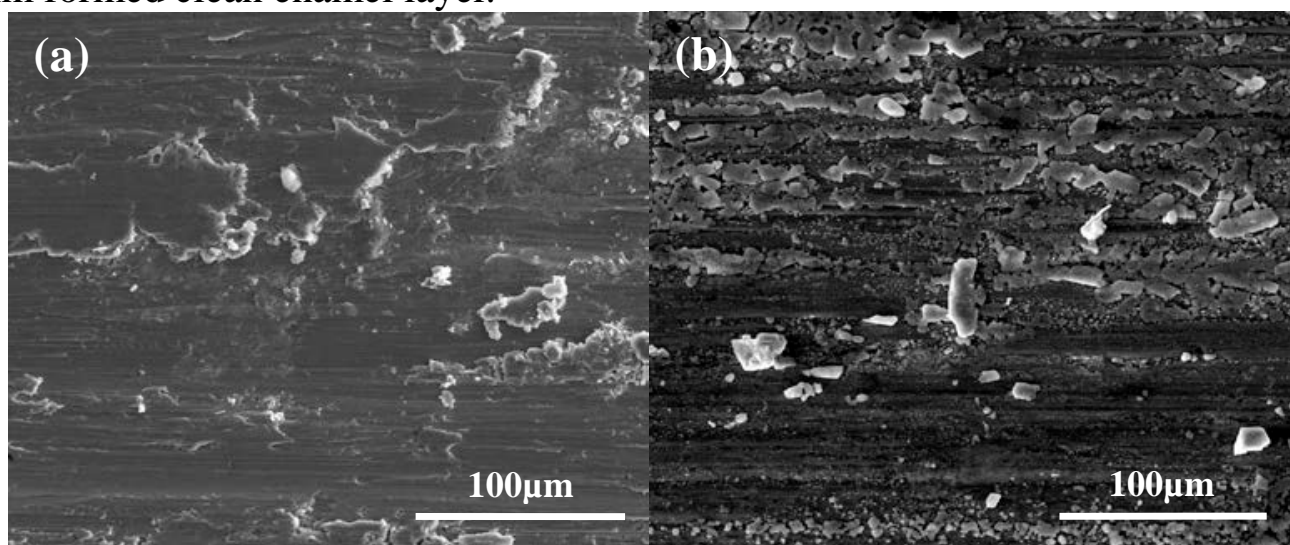

Fig.4 SEM images of worn tracks on the disc lubricated by PETE with and without synthesized perrhenate at $600^{\circ} \mathrm{C}$

(a) PETE (b) PETE+SA+0.5wt\%Ca( $\left(\mathrm{ReO}_{4}\right)_{2}$ 
The XPS analysis was carried out to explore the chemical composition of the several typical elements of the corresponding antifriction layer on the worn scar after friction test at $600^{\circ} \mathrm{C}$. Fig. 6 shows the XPS characteristic spectrum of the disc surface. In the presence of the data, it can be seen that the peaks of C1s were located at bonding energy of $284.5 \mathrm{eV}$, which were identified as $\mathrm{C}-\mathrm{H}$ chain in PETE. This was attributed to the chemical absorption of base oil on the disc surface. The Fe2p peak locating around $710.8 \mathrm{eV}$ was ascribed to the generation of iron oxide $\left(\mathrm{Fe}_{3} \mathrm{O}_{4}\right)$. The peak value of Ni2p was at about $853.7 \mathrm{eV}$, which resulted from the appearing of the NiO. These suggested that the tribochemical reaction had occurred during the lubricating process. It was confirmed that the perrhenates additive directly participated the formation of the antifriction layer. For example, a $\mathrm{Cu} 2 \mathrm{p}$ peak appeared around $934.1 \mathrm{eV}$, illustrating that the $\mathrm{Cu}$ originated from the $\mathrm{Cu}$ perrhenate additive in base oil had been on the surface of the wear scar. This indicated there was a strong absorption of additive or decomposition compound containing copper during the testing. As a result, the tribochemical reaction layer in connection with the antifriction and lubricating perrhenates additive deposited on the worn track surface contributed to remarkably improve the wear resistance of the rubbing pairs.
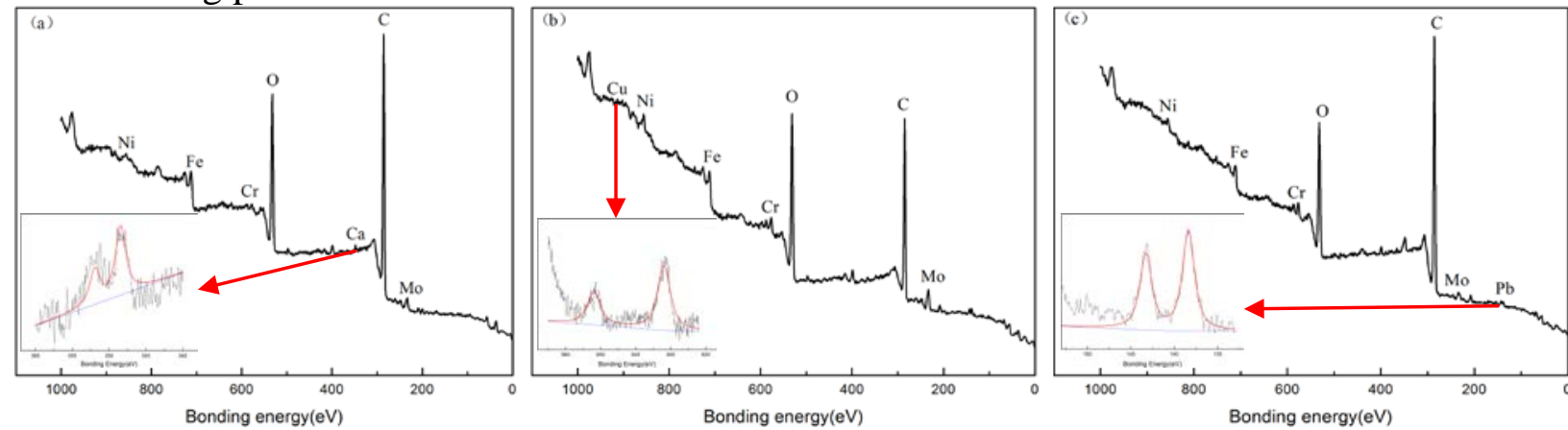

Fig. 5 XPS spectra of typical elements on the worn track surface of the tested disc lubricated with base oil containing different additives at $600^{\circ} \mathrm{C}$
(a) PETE+SA+0.5wt\% $\mathrm{Ca}\left(\mathrm{ReO}_{4}\right)_{2}$
(b) $\mathrm{PETE}+\mathrm{SA}+0.5 \mathrm{wt} \% \mathrm{Cu}\left(\mathrm{ReO}_{4}\right)_{2}$
(c) PETE $+\mathrm{SA}+0.5 \mathrm{wt} \%$

$$
\mathrm{Pb}\left(\mathrm{ReO}_{4}\right)_{2}
$$

\section{Conclusions.}

1. The addition of perrhenates to the PETE base oil remarkably improved the antifriction behavior in the high temperature section. The friction coefficients of oil containing perrhenates additive decreased at $600^{\circ} \mathrm{C}$, especially the friction coefficient of lead perehenate was below 0.2. Meanwhile no evident abrasion or deformation appeared at the worn track in the experimental time span.

2. The perrhenates additive plays an important role in the formation layer during the test process under high temperatures. This antifriction layer can be smeared uniformand existed stably in the worn track.

\section{Acknowledgements}

This project reported here was supported by Discipline Content Education Project of SJZU (No. XKHY2-122), Postdoctoral innovation fund of SJZU (No. SJZUBSH201616), and Youth fund of SJZU (2015127).

\section{References}

[1] Allam IM. Solid lubricants for applications at elevated-temperatures-a review[J]. Journal of Materials Science, 1991, 26: 3977-3984.

[2] Martina JM., Pascala H, Donneta C, et al. Superlubricity of $\mathrm{MoS}_{2}$ : crystal orientation mechanisms[J]. Surface \& Coatings Technology, 1994, 68-69: 427-437. 
[3] Huang HD, Tu JP, Gan LP. An investigation on tribological properties of graphite nanosheets as oil additive[J]. Wear, 2006, 2: 140-144.

[4] Li SZ, Jiang XX, Peterson MB, et al. Fundamental of lubrication with oxide film of Ni-Cu-Re at elevated temperature[J]. Materials Science Progress, 1990, 4(1), 1-7 (in Chinese).

[5] Sliney HE. Solid lubricant materials for high temperatures-a review[J]. Tribology International,1982, 15(5): 303-315.

[6] Varfolomeev MB, Zemenkova AN, Chrustalev VN, et al. Crystal structrue of copper perrhenate tetrahydrate, $\mathrm{Cu}\left(\mathrm{ReO}_{4}\right)_{2} \cdot 4 \mathrm{H}_{2} \mathrm{O}[\mathrm{J}]$. Journal of Alloys and Compounds, 1994, 215: 339-343.

[7] Butz A, Miehe G, Paulus H, et al. The Crystal Structures of $\mathrm{Mn}\left(\mathrm{ReO}_{4}\right)_{2} \cdot 2 \mathrm{H}_{2} \mathrm{O}$ and of the Anhydrous Perrhenates $\mathrm{M}\left(\mathrm{ReO}_{4}\right)_{2}$ of Divalent Manganese, Cobalt, Nickel, and Zinc[J]. Jounal of solid state chemisty, 1998, 138: 232-237. 